\title{
Plane warts on the back of the hand successfully treated with oral isotretinoin
}

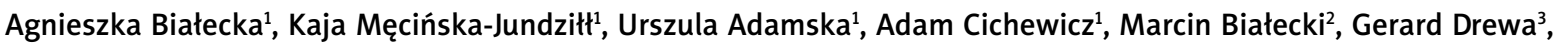 \\ Rafał Czajkowski ${ }^{1}$
}

${ }^{1}$ Chair of Dermatology, Sexually Transmitted Diseases and Immunodermatology, Faculty of Medicine in Bydgoszczy, Copernicus University in Torun, Poland

2Department of Radiology and Diagnostic Imaging, Nicolaus Copernicus University in Torun, Collegium Medicum in Bydgoszcz, Poland ${ }^{3}$ University of Bydgoszcz, Bydgoszcz, Poland

A 31-year-old female was admitted to the Dermatology Clinic because of fine, skin-colour, shiny surface papules on the back of both hands (Figure $1 \mathrm{~A}$ ). These skin lesions were present for several months, and periodically were associated with pruritus. The pathology exacerbated following an acute sinusitis treated with antibiotic cefuroxime. Plane warts were diagnosed based on the medical history and the clinical presentation. The patient was initially treated with cryosurgery and laser therapy. Subsequently, topical pharmacotherapy was applied: imiquimod cream, podophyllotoxin liquid, fluorouracil ointment, tretinoin liquid and monochloride acetic acid liquid in a few weeks' time period. Dissemination of fresh dermatological changes was observed peripherally and in vicinity of lesions treated with monochloride acetic acid and laser therapy (Figure $2 \mathrm{~A}$ ). Afterwards, the patient received isoprinosine at a daily dose of $4 \mathrm{~g}$, with no evident improvement. Considering the exacerbation of dermal changes and lack of any improvement, a decision was made to introduce the oral form of isotretinoin at a daily dose of $0.5 \mathrm{mg} / \mathrm{kg}$ b.w. After three weeks of this treatment a complete remission was achieved. Only scars left by previously applied treatments were observed (Figures 1 B, 2 B). Adverse effects of the treatment included dryness and exfoliation of the red zone of lips and dryness of conjunctiva of eyes. The treatment was continued for 3 months. At present the patient is followed-up.

Plane warts are dermatological lesions caused by the human papilloma virus (HPV), predominantly by types 3 and 10. The condition most often develops in young people and occupies the visible surfaces of the skin, such as the forehead and chin on the face and backs of hands. The diagnosis is based mainly on the clinical presentation.

The most commonly applied therapeutic methods include topical retinoids, usually tretinoin, isotretinoin, tazarotene, as ointments or liquids. However, topical retinoids are associated with numerous adverse effects leading to the development of erythaema, exfoliation, and skin irritation. In case of chronic treatment those may be noxious, as they occur in visible areas of the skin. Moreover, immunomodulating formulas are used, including imiquimod cream, as well as anti-mitotic drugs, such as fluorouracil liquid or ointment, and podophyllotoxin liquid. These preparations may also evoke a local hypersensitivity reaction. Majority of topical medicinal products are not registered to be used in children. Most commonly used surgical treatments include cryosurgery, electrocoagulation and laser removal of the skin lesions. However, these methods are associated with a scarification risk and are expensive. Even radical surgical removal of dermatological changes does not guarantee a complete remission. Occasionally the treatment of warts lasts for months or years, leading to a significant reduction of patients' well-being and quality of life. Patients are aware of the viral aetiology of their condition and are afraid of dissemination of the lesions, thus they avoid close contacts with family and friends. The Koebner phenomenon is observed, that is during an active phase of the disease new lesions disseminate within 8-14 days in a place of an injury. Face and backs of hands are often exposed to mechanical injury. Spontaneous resolution of the skin changes with no pharmacotherapy is possible within 2 first years of the disease, but it is rarely observed.

Address for correspondence: Agnieszka Białecka MD, Chair of Dermatology, Sexually Transmitted Diseases and Immunodermatology, Faculty of Medicine, Nicolaus Copernicus University, 9 Skłodowskiej-Curie St, 85-094 Bydgoszcz, Poland, phone: +48 $696557558,+48535854$ 568, e-mail: agnieszka_bialecka@wp.pl Received: 13.07.2017, accepted: 24.08.2017. 

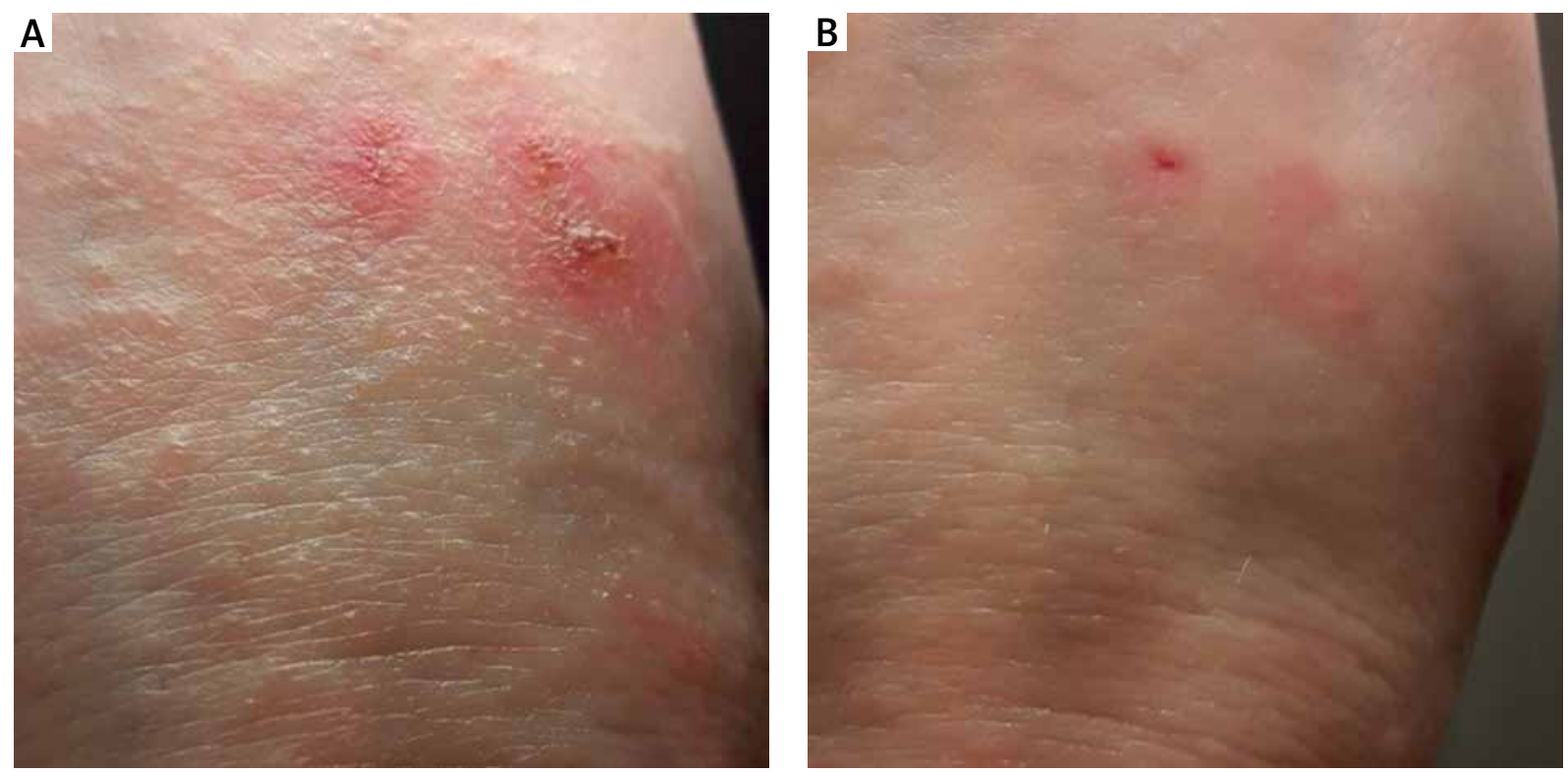

Figure 1. Left hand. A - Visible numerous lesions of flat warts. B - Remission of lesions after 3 weeks of oral isotretinoin therapy
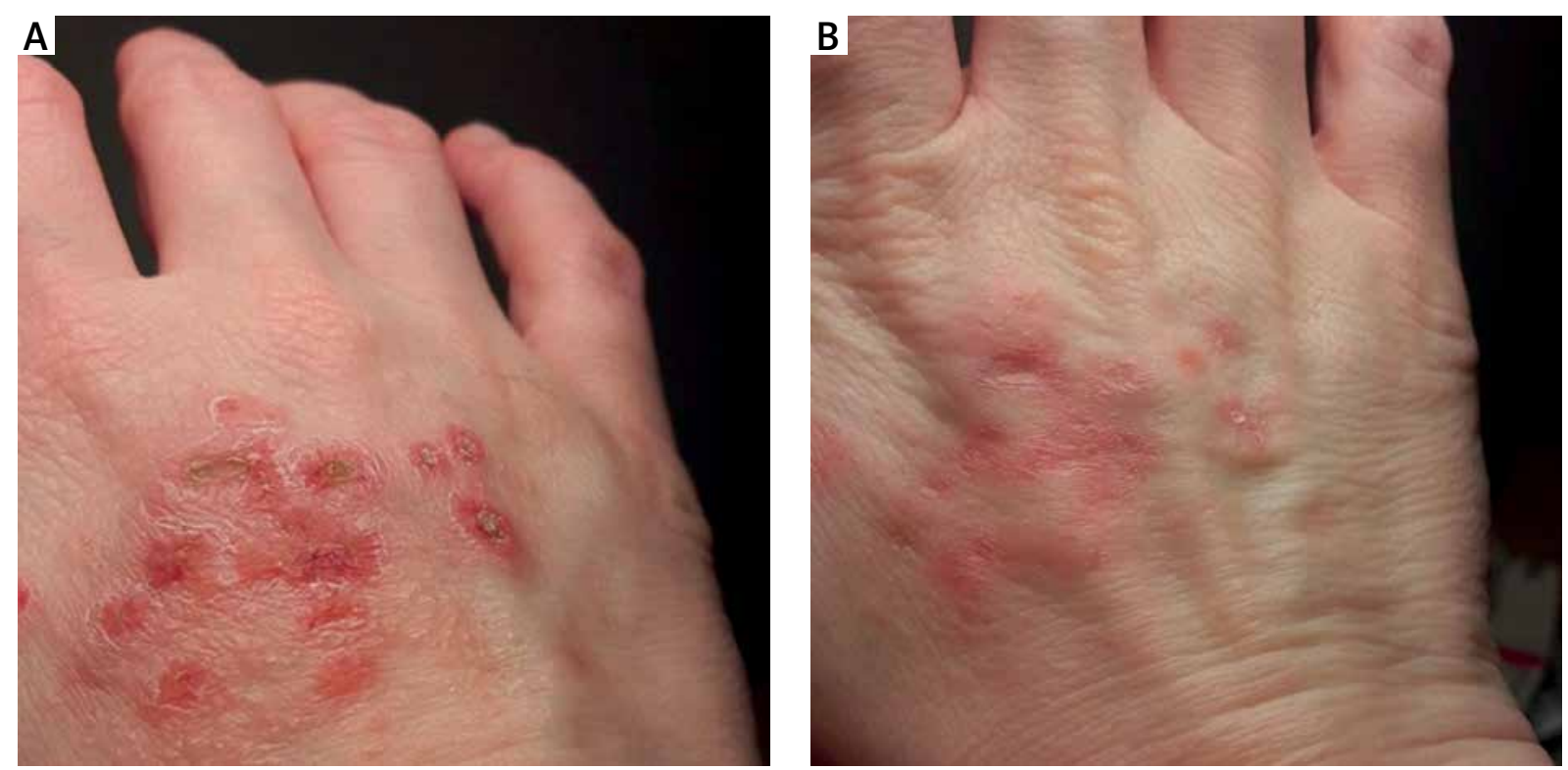

Figure 2. Right hand. A - Visible numerous new warts around the lesions treated with laser therapy and with monochloride acetic acid. $\mathbf{B}$ - Remission of lesions after 3 weeks of oral isotretinoin treatment. Only the scar is visible

Absence of effective systemic therapy for plane warts prompted attempts to use oral isotretinoin for the treatment of the disease. Isotretinoin is a synthetic derivative of vitamin A and a stereoisomer of all-trans-retinoic acid. Its precise mechanism of action remains unclear. The use of isotretinoin reduces the activity of sebaceous glands and leads to their involution. Proliferation of sebaceous glands is inhibited, and their differentiation normalises. The drug also elicits a weak anti-inflammatory and antineoplastic action [1]. Isotretinoin is currently approved only in severe forms of acne. However, retinoids, both systemic and topical, are also used in other diseases, including psoriasis, lichen planus, pityriasis rubra pilaris, Darier's disease, ichthyosis, solar keratosis, oral leucoplakia, Xeroderma pigmentosum, keratoacanthoma, spinocellular carcinoma, dermatological forms of T-cell lymphomas, lupus erythematosus, rosacea, and hidradenitis suppurativa [1, 2].

Reports on use of oral isotretinoin in the treatment of plane warts are scarce. Single cases of successful 
treatment of facial warts with a drug dose of 0.3 and $0.4 \mathrm{mg} / \mathrm{kg}$ b.w. were reported [3]. Study results published in 2012 demonstrated $73 \%$ of complete remissions in patients with facial plane warts treated with isotretinoin at a dose of $0.5 \mathrm{mg} / \mathrm{kg}$ b.w. [4]. In 2014, a double-blind, randomized, placebo-controlled trial of patients with facial plane warts treated with oral isotretinoin at a dose of $30 \mathrm{mg} /$ day demonstrated a complete remission in 100\% of patients using the active drug and in none of placebotreated subjects [5].

Nevertheless, the currently reported case is the first described application of oral isotretinoin for the treatment of plane warts of backs of hands.

Several reports also indicate efficacy of isotretinoin in genital warts caused by HPV 6 and 11 . Studies on the use of oral isotretinoin for the treatment of genital warts were started in the 1980s [6]. Reports comparing efficacy of interferon $\alpha$ compared with isotretinoin in the treatment of genital warts are also noteworthy $[7,8]$. The first one, published in 1995, demonstrated that combined therapy resulted in a higher remission rate compared to isotretinoin alone. In the second study, the remission rate was similar in both subgroups, and reached the level of 70-80\%, which prompts for the treatment with isotretinoin alone with no threat of interferon-induced adverse effects.

It was demonstrated that besides a strong immunomodulating effect isotretinoin had a radical effect on differentiation and proliferation of epithelial cells. Isotretinoin also induced apoptosis in HPV-infected cells [9]. As HPV replication is associated with the level of differentiation of keratinocytes, it is supposed that isotretinoin inhibits DNA replication in invaded cells and so it causes remission of skin lesions $[10,11]$. There are also some reports available, confirming the efficacy of isotretinoin in treatment of cervical condylomata acuminata [12], complete remission was achieved in $32 \%$ of patients, and a partial remission in nearly $40 \%$.

Treatment with the isotretinoin is associated with an obligatory use of effective contraception in women of childbearing potential, regular clinical follow-up, and periodic laboratory testing. The most commonly observed adverse effects of the treatment with isotretinoin are dryness of skin and mucosa, exfoliation of the red zone of lips, transient increase in serum aminotransferase and triglyceride levels. Despite the above-mentioned potential adverse effects, the achievable remission seems to be a great advantage. Patients are not exposed to the risk of scarification or local hypersensitivity reactions. Lesions in visible parts of the skin disappear, which leads to a great improvement in the mental comfort. The treatment with isotretinoin should be considered in patients with plane warts in whom remission could not be achieved with available surgical methods and topical treatments.

\section{Conflict of interest}

The authors declare no conflict of interest.

\section{References}

1. Akyol M, Ozçelik S. Non-acne dermatologic indications for systemic isotretinoin. Am J Clin Dermatol 2005; 6: 175-84.

2. Torzecka JD, Dziankowska-Bartkowiak B, Gerlicz-Kowalczuk Z, Wozniacka A. The use of isotretinoin in low doses and unconventional treatment regimens in different types of acne: a literature review. Adv Dermatol Allergol 2017; 34: 1-5.

3. Miljkovic J. A novel therapeutic approach to plane warts: a report on two cases. Acta Dermatovenerol Alp Pannonica Adriat 2012; 21: 63-4.

4. Al-Hamamy HR, Salman HA, Abdulsattar NA. Treatment of plane warts with a low-dose oral isotretinoin. ISRN Dermatol 2012; 2012: 163929.

5. Olguin-García MG, Jurado-Santa Cruz F, Peralta-Pedrero ML, Morales-Sánchez MA. A double-blind, randomized, placebocontrolled trial of oral isotretinoin in the treatment of recalcitrant facial flat warts. J Dermatolog Treat 20152; 6: 78-82.

6. Olsen EA, Kelly FF, Vollmer RT, et al. Comparative study of systemic interferon alfa-nl and isotretinoin in the treatment of resistant condylomata acuminata. J Am Acad Dermatol 1989; 20: 1023-30.

7. Cardamakis E, Kotoulas IG, Relakis K, et al. Comparative study of systemic interferon alfa-2a plus isotretinoin versus isotretinoin in the treatment of recurrent condyloma acuminatum in men. Urology 1995; 45: 857-60.

8. Cardamakis EK, Kotoulas IG, Dimopoulos DP, et al. Comparative study of systemic interferon alfa-2a with oral isotretinoin and oral isotretinoin alone in the treatment of recurrent condylomata acuminata. Arch Gynecol Obstet 1996; 258: 35-41.

9. Tsambaos D, Zimmermann B. Effects of synthetic retinoids on cellular systems. In: Psoriasis. $2^{\text {nd }}$ edn. Roenigk H Jr, Maibach H (eds). Marcel Dekker Inc., New York 1991; 659-707.

10. Lutzner MA, Blanchet-Bardon C, Puissant A. Oral aromatic retinoid (Ro 10-9359) treatment of two patients suffering from the severe form of epidermodysplasia verruciformis. In: Retinoids: Advances in Basic Research and Therapy. Orfanos CE, Braun-Falco O, Farber EM (eds). Springer-Verlag, New York 1981; 407-10.

11. Pasmatzi E, Kapranos N, Monastirli A, et al. Large benign condyloma acuminatum: successful treatment with isotretinoin and interferon alpha. Acta Derm Venereol 2012; 92: 249-50.

12. Georgala S, Katoulis AC, Georgala C, et al. Oral isotretinoin in the treatment of recalcitrant condylomata acuminata of the cervix: a randomised placebo controlled trial. Sex Transm Infect 2004; 80: 216-8. 